\title{
Un acercamiento al etnocidio y al genocidio desde Pierre Clastres. La construcción de la otredad en las últimas dictaduras militares del Cono Sur latinoamericano ${ }^{1}$
}

\author{
An approach to ethnocide and genocide from Pierre \\ Clastres. The construction of otherness in the last military \\ dictatorships of South America
}

Uma aproximação ao etnocídio e ao genocídio desde Pierre Clastres. A construção do Outro nas últimas ditaduras do Cone Sul latino-americano

Dra. Mariela Cecilia Avila²

Recibido: 18 de marzo de 2018 - Aceptado: 26 de abril de 2018

\begin{abstract}
Resumen
En el presente artículo se reflexiona sobre la construcción de un "Otro" durante las últimas dictaduras militares del Cono Sur latinoamericano. Para ello, se hace uso de las categorías de "genocidio" y "etnocidio" desde la perspectiva del antropólogo Pierre Clastres. El análisis permite poner en diálogo dichas categorías con el modo en que se identificó y configuró una individualidad considerada una amenaza para el modelo político y económico que se buscaba implementar. Se explicita aquí el modo en que la construcción de una otredad disidente ameritó prácticas de tortura, muerte y exilio, en aras de la construcción de
\end{abstract}

1 Este artículo forma parte del Proyecto de Iniciación FONDECYT N ${ }^{\circ} 11160148$ "Re-pensar el exilio: ampliaciones de sentido para un análisis filosófico en clave latinoamericana."

2 Argentina, Dra. en Filosofía por la Pontificia Universidad Católica de Valparaíso y por la Universidad París 8 Saint-Denis. Académica e investigadora de la Escuela de Filosofía de la Universidad Católica Silva Henríquez. Contacto: mavila@ucsh.cl 
un proyecto político unitario y hegemónico que no admitía posibles diferencias.

Palabras clave: Pierre Clastres- genocidio- etnocidio- Otro- dictaduras militares latinoamericanas

\begin{abstract}
This article reflects on the construction of "otherness" during the last military dictatorships of Latin America. For this, categories of "genocide" and "ethnocide" are used from anthropologist Pierre Clastres' perspective. The analysis puts these categories in dialogue about how an individuality was identified and configured as a threat to the political and economic model to be implemented. It makes explicit the way in which the construction of a dissident otherness deserved practices of torture, death and exile, in order to build a unitary and hegemonic political project that did not admit possible differences.
\end{abstract}

Keywords: Pierre Clastres- genocide- ethnocide- Other- Latin American military dictatorships

\title{
Resumo
}

No presente artigo reflexiona-se filosoficamente sobre a construção de um Outro durante as últimas ditaduras militares do Cone Sul latino-americano. Para aquilo, se faz uso das categorias de "genocídio" e "etnocídio" desde a perspectiva do antropólogo Pierre Clastres. A análise permite pôr em diálogo ditas categorias com o modo em que se identificou e configurou uma individualidade considerada una ameaça para o modelo político e econômico que se buscava implementar. Explicita-se aqui o modo em que a construção de um outro dissidente envolveu práticas de tortura, morte e exílio, em prol da construção de um projeto político unitário e hegemônico que não admitia possíveis diferenças.

Palavras-chave: Pierre Clastres- genocídio- etnocídio- Outro- ditaduras latino-americanas

\section{A modo de introducción}

\section{Pareciera ser que la presencia de un $\mathrm{Otro}^{3}$ como lo opuesto a lo propio, es decir, al nosotros de la comunidad, atraviesa los distintos modos}

3 El Otro que se analiza en este trabajo no es el Autre del psicoanálisis que presenta Jacques Lacan. Si bien existen diversas lecturas que permitirían relacionar emparentar el tema de este artículo con el psicoanálisis, esto no se hará en la presente investiga- 
de configuración social a lo largo de la historia. Ese "enemigo" que queda fuera de la unidad -en contraposición al "amigo", si se piensa en la distinción que establece Carl Schmitt en Teoría del Partisano (Orestes Aguilar 2004)- es parte del modo en que se constituyen las comunidades, tanto en sus desarrollos políticos, como en su autopercepción y enunciación subjetiva. El elemento considerado ajeno al conjunto no sólo cumple el rol de encarnar lo Otro diverso, sino también de reforzar la unidad desde su diferencia. En efecto, a partir de la otredad se pone de manifiesto una unidad que expulsa, y que en gran medida se constituye al efectuar tal expulsión. Las formas de organización política y social desde sus ordenamientos más primitivos parecen afirmar esta mecánica, en la que lo propio se intensifica en base a la distinción con un Otro que, en tanto individualizado y expulsado, es puesto en bando de la comunidad, ya que encarna lo que no se es, ni se debe ser.

Desde esta perspectiva, se busca vislumbrar y analizar ciertas mecánicas existentes durante los últimos gobiernos militares del Cono Sur latinoamericano, desde las que se caracterizó, identificó y construyó una otredad particular: la de un individuo subversivo, peligroso y sacrificable -en términos agambenianos (2006). La construcción de dicha otredad fue una tarea clave en la polarización, fáctica y simbólica del cuerpo de la población, ya que su constitución generó un dispositivo de estructuración social. Así, la sola existencia de ese Otro que representaba lo ominoso, admitía la violencia y la muerte, pues su presencia era una suerte de regulador del tejido social, que demarcaba claros límites entre lo permitido y lo prohibido.

Para ampliar estos análisis, se acude al trabajo del antropólogo Pierre Clastres que permite una novedosa reflexión, pues su mirada etnográfica da cuenta del modo en que, desde las sociedades primitivas, se ha puesto en juego la identificación de una otredad como fruto de mecánicas de construcción social e histórica, y no simplemente

ción, pues este desarrollo excedería el marco conceptual y analítico que se pretende alcanzar con este trabajo. 
de un devenir natural. En general, y a grandes rasgos, se puede decir que el análisis de Clastres se aboca a mostrar y analizar la existencia de sociedades sin Estado, es decir, sociedades que mantienen otra relación con el poder, sobre todo desde la perspectiva económica. Sin embargo, tal como Clastres indica en La sociedad contra el Estado de 1974 (2008 161), observar la ausencia de la conformación estatal como una carencia o un momento primitivo de organización social, no haría más que acentuar el rasgo etnocéntrico del observador. En relación también con la categoría de etnocentrismo, pero esta vez en relación a la categoría de genocidio, en su texto "Sobre el etnocidio" del año 1974 (Clastres 2001 55), el antropólogo desarrolla una interesante reflexión a partir de la otredad. Es principalmente en este trabajo, publicado en la compilación Investigaciones en Antropología Política $^{4}$ (2001), donde Clastres se explaya en el análisis que creemos sería posible extender a otros sucesos y que permitiría iluminar diversos procesos históricos de construcción de una otredad. De este modo, se busca desplegar aquí una clave de lectura para pensar el modo en que la unidad se constituye siempre sobre la base de la violencia, el terror y la aniquilación. En efecto, será el desarrollo clastreano de las categorías de genocidio y etnocidio, el que permitirá analizar la construcción de la otredad en los procesos dictatoriales del Cono Sur latinoamericano.

Interesa indicar de modo explícito que esta investigación no se inscribe en el ámbito de los análisis sobre el genocidio en general, ni sobre el genocidio de las últimas dictaduras latinoamericanas en particular ${ }^{5}$, aun cuando no se pierdan de vista los aportes de este campo de estudio. Ciertamente, la intención específica y delimitada de este escrito es la de pensar filosóficamente la construcción del Otro en un contexto dictatorial latinoamericano, haciendo uso -y quizá abuso- de las nociones de genocidio y etnocidio como las presenta Pierre Clastres.

4 Esta compilación, bajo el nombre de Recherches d'anthropologie politique, fue publicada por primera vez por Éditions du Seuil, en el año 1980.

5 Para abordar esto, ver Feierstein, Daniel (2007) El genocidio como práctica social. Entre el nazismo y la experiencia argentina. Buenos Aires, Fondo de Cultura Económica. 


\section{Genocidio y etnocidio: la mirada de Clastres}

Para comenzar el análisis, se presentarán aquellas categorías que oficiarán de hilo conductor para este escrito: las de etnocidio y genocidio. Al respecto, Clastres indica que estas prácticas son mucho más antiguas que los vocablos que las nominan. Indica también que, si bien y de modo específico el término etnocidio tiene su origen en la disciplina etnográfica contemporánea, su uso ha sobrepasado el propio ámbito disciplinar, instalándose discursivamente como un concepto de usanza común. Es precisamente esta ampliación discursiva la que lleva al etnógrafo a sospechar de la actual utilización del término, y a preguntarse si este vocablo mantiene aún el sentido con el que fue creado.

En este sentido, si bien el término etnocidio complementa y da un alcance más amplio al de genocidio, que es más conocido, esto que no implica dejar de lado ciertas diferencias estructurales fruto de sus orígenes en fenómenos distintos. Una de las diferencias principales reside en el carácter jurídico que posee originalmente el término genocidio, ámbito que se encuentra excluido en el caso del etnocidio. Así, en sus comienzos, la puesta en circulación del vocablo genocidio tuvo como fin nominar un nuevo tipo de criminalidad, que parecía no ser conocida con anterioridad en la historia. En este sentido, señala el autor:

"Creado en 1946 durante el proceso de Nüremberg, el concepto jurídico de genocidio es la toma de conciencia en el plano legal de un tipo de criminalidad desconocida hasta el momento. Más exactamente, remite a la primera manifestación, debidamente registrada por la ley, de esta criminalidad: el exterminio sistemático de los judíos europeos por los nazis alemanes." (Clastres 1996 55).

La necesidad de creación de un nuevo término, y en particular de este término, bien puede pensarse a la luz de la reflexión de Hannah Arendt, quien insiste en lo fundamental de la incorporación de nuevos modos de análisis para leer la realidad. En efecto, es la imprevisibilidad de ciertos fenómenos la que pone en evidencia el agotamiento de las herramientas tradicionales de reflexión y comprensión (Arendt, 1987 1990). La urgencia en la creación de nuevos conceptos que enuncia 
Arendt, parece coincidir con la reflexión de Clastres sobre los orígenes del término genocidio, cuya puesta en circulación se retrotrae a la finalización de la Segunda Guerra Mundial. La exigencia de dar nombre a aquellos acontecimientos que no pueden enmarcarse dentro de los fenómenos ya conocidos, da cuenta de un complejo proceso de comprensión, que implica reconocer el azar, la libertad y la novedad como partes constitutivas del devenir histórico (Arendt, 1990) ${ }^{6}$.

Ahora bien, en este punto Clastres aclara que, si bien la matanza judía puede ser considerada como el primer crimen masivo de carácter genocida en ser registrado y juzgado por la ley, en ningún caso es el primero con estas características en la historia. En efecto, en diversos momentos históricos es posible observar numerosos crímenes genocidas, como por ejemplo el sistemático asesinato de los pueblos originarios de América, la matanza armenia o la aniquilación masiva en el Congo, entre otros. En esta misma línea, los crímenes de corte colonialista durante el periodo expansionista europeo, evidencian una relación antigua y duradera entre violencia, muerte, nacimiento y prácticas políticas asesinas, que ha cristalizado en distintos momentos de la historia y en diversos puntos del mapa mundial. Sin embargo, la creación específica del término genocidio, en tanto concepto jurídico en el siglo XX, lejos de invalidar o invisibilizar estos sucesos previos, otorga un nuevo marco legal y una nueva matriz de análisis para pensar todas estas catástrofes. Así, el estatuto jurídico de genocidio permitiría iluminar otros acontecimientos históricos de igual raíz aniquiladora.

6 En efecto, la historia se constituye, para Arendt, como una cristalización acontecimientos, cuyos efectos pueden ser completamente novedosos, y por lo mismo rechazan toda posibilidad de encuadre en otros sucesos y acontecimientos reconocidos en y por la historia. Desde esta perspectiva, vislumbrar la historia como una cristalización de sucesos aleatorios otorga un importante lugar al azar y a la libertad dentro de la configuración del presente. Para una mayor profundización de este tema Cfr. Avila, Mariela. "Narración y comprensión: el lugar de la memoria en la obra de Hannah Arendt". Revista El Banquete de los Dioses. Revista de Filosofía y Teoría Política contemporáneas. Instituto de Investigaciones Gino Germani, Universidad de Buenos Aires. Vol. 3 N $^{\circ}$ 5, Pp. 54-71. ISSN 2346-9935. 
En esta línea, tomando el genocidio judío como hito histórico, a partir de 1948, las Naciones Unidas adoptan el documento llamado Convención para la Prevención y la Sanción del Delito de Genocidio ${ }^{7}$ que, al igual que la Corte Penal Internacional, mediante el Estatuto de Roma, lo definen de la siguiente manera:

"Se entiende por genocidio cualquiera de los actos mencionados a continuación, perpetrados con la intención de destruir total o parcialmente a un grupo nacional, étnico, racial o religioso como tal: a) matanza de miembros del grupo; b) lesión grave a la integridad física o mental de los miembros del grupo; c) sometimiento intencional del grupo a condiciones de existencia que hayan de acarrear su destrucción física, total o parcial; d) medidas destinadas a impedir nacimientos en el seno del grupo; e) traslado por la fuerza de niños del grupo a otro grupo." (Feierstein 2007 40-41).

Como puede verse a partir de esta definición, y tal como su nombre lo indica, las prácticas genocidas tienen su raíz en la diferencia racial, étnica, nacional o religiosa y su finalidad es, precisamente, la destrucción de grupos humanos que comparten algunas de estas características. Al hablar de genocidio, se hace alusión de modo específico a crímenes físicos de índole racial, que buscan hacer desaparecer inmediatamente a pueblos enteros. Nótese en este punto la importancia que tiene el factor temporal, pues volveremos a ello más adelante.

No obstante, al leer esta definición llama la atención que en ningún punto se aluda al factor político como fuente del acto genocida. Esta compleja situación ha sido advertida en diversos informes jurídicos entre los que destacan, según Daniel Feierstein (2007), el Informe Whitaker, el informe del Juez español Baltasar Garzón y el documento del Tribunal Penal Internacional, que se refiere a las matanzas ocurridas en los Balcanes y en Ruanda. Tanto la información que portan dichos documentos, como los diversos casos de matanzas políticas masivas catalogables 
como genocidas, dan cuenta de la necesidad de ampliar la definición de este tipo de criminalidad al ámbito de lo político y de lo ideológico.

Por otra parte, y refiriéndose directamente al etnocidio, Clastres indica que, si bien en sus comienzos este término tendió a ser considerado un sinónimo de genocidio, su aparición implica una novedad, pues toma en cuenta e introduce la variable cultural en el contexto. Ciertamente, el etnocidio alude a crímenes culturales o espirituales, -como los llama el antropólogo. Aquello que las prácticas etnocidas buscan asesinar no reside sólo en el cuerpo, sino que se dirige a finiquitar modos de vida. El etnocidio se despliega sobre aquellas formas de vida diferentes, culturalmente diversas, que son cuestionadas y no son consideradas lo suficientemente dignas como para ser parte de la unidad, o de la comunidad.

Ahora bien, es importante notar que aunque genocidio y etnocidio no aludan al mismo fenómeno, una práctica no excluye a la otra, sino que por el contrario, en la mayoría de los casos se complementan. Si hubiese que marcar una distinción entre ambas nociones, la más evidente sería la de la variable temporal. En efecto, mientras que los efectos de la aniquilación genocida son inmediatos, las consecuencias del etnocidio se perciben con mayor claridad con el paso del tiempo:

"En suma, el genocidio asesina los cuerpos de los pueblos, el etnocidio los mata en el espíritu. Tanto en uno como en otro caso se trata sin duda de la muerte, pero de una muerte diferente: la supresión física es inmediata, la opresión cultural difiere largo tiempo sus efectos, según la capacidad de resistencia de la minoría oprimida." (Clastres 1996 56).

Si el elemento que distancia el genocidio del etnocidio es la variable temporal, pues sus efectos se evidencian en momentos distintos, aquel que los acerca dice relación con la visión de Otro. Aun asumiendo que uno de los puntos de confluencia entre ambas prácticas es la visión de un Otro, la relación que se mantiene con esa otredad es distinta. En efecto, mientras que en el caso del genocidio la diferencia con un Otro amerita su aniquilación, el etnocidio, ante la misma diferencia, busca una modificación. En esta línea, se podría decir que el fundamento de 
las prácticas etnocidas es la perfectibilidad del Otro, pues mediante una adecuada educación o transformación, se puede erradicar la diversidad al punto de convertirlo en un igual.

Siguiendo este hilo reflexivo, Clastres muestra cómo el etnocidio se entronca directamente con la noción de "etnocentrismo", pues el parámetro de comparación entre pueblos o civilizaciones tiene como punto de referencia siempre la propia cultura, que es considerada superior a las demás en todos los aspectos. En su trabajo etnográfico con pueblos primitivos latinoamericanos, el antropólogo nota que cada una de estas culturas se denomina a sí misma como "los hombres", mientras que el resto de los pueblos es caracterizado a partir de vocablos peyorativos. "Toda cultura realiza así una división de la humanidad entre ella misma, que se afirma como representación de lo humano por excelencia, y los otros, que participan mínimamente de la humanidad" (Clastres 1996 58-59).

No obstante, y esto es importante notarlo, el hecho que toda cultura presente rasgos etnocéntricos no significa que pueda llegar a ser etnocida, ya que etnocentrismo y etnocidio en ningún caso son sinónimos. No toda práctica etnocéntrica ha desencadenado etnocidios, y yendo aún más lejos, Clastres indica que el germen del etnocidio pareciera estar inserto solamente en la cultura occidental y, de modo particular, en su organización bajo la forma del Estado. Si bien esta tesis es ampliamente discutible, y ya se explicó al comienzo que la finalidad de Clastres es mostrar la posibilidad de existencia y supervivencia de las sociedades más allá de la figura del Estado, resulta por demás interesante seguir la línea argumentativa del autor. Con el fin de fundamentar esto, el etnólogo desarrolla un análisis histórico-genealógico de la cultura occidental, evidenciando el lugar primordial que ocupan las prácticas etnocidas al interior de la estructura del Estado. En este sentido, la organización política del Estado -ausente en las culturas primitivas americanas según Clastres- da cuenta de una praxis que busca reducir lo múltiple a la unidad, lo que implica aniquilar toda diferencia y diversidad:

"La violencia etnocida, como negación de la diferencia, pertenece a la esencia del Estado, tanto en los imperios 
bárbaros como en las sociedades civilizadas de Occidente: toda organización estatal es etnocida, el etnocidio es el modo normal de existencia del Estado." (Clastres 1996 62).

En este punto es necesario notar que cuando Clastres habla de Estado, no sólo hace referencia a la forma organizacional europea y moderna, sino que considera esta estructura como un modo de organización política particular que se desarrolla alrededor de la producción. En este contexto analítico, la negación y reducción de la diferencia a una unidad homogénea, tiene que ver directamente para el antropólogo con las necesidades de la producción. Entonces, desde la perspectiva clastreana, y ante un escenario de organización política y económica de estructura estatal, la diversidad del Otro puede ser reeducada y conducida a la unidad mediante prácticas de carácter etnocida, mientras que el genocidio tendrá por fin aniquilar diferencia y disidencia: "El primero proclama la jerarquía de las culturas: las hay inferiores y superiores. El segundo confirma la superioridad absoluta de la cultura occidental" (1996 58).

Si extendemos esta reflexión a la configuración actual del Estado, se podría decir que la vida considerada de modo positivo y deseable es la occidental y su sistema capitalista de producción. Toda forma de vida que altere los valores y prácticas políticas, sociales y económicas de este tipo de estructura, se transforma en una complicación que podría perturbar el orden y la paz tan difícilmente alcanzado luego de las catástrofes que asolaron el siglo XX. Dado lo anterior, la presencia inquietante y problemática que encarna la diferencia, desencadena y propicia prácticas genocidas y etnocidas por parte de los Estados occidentales contemporáneos, tanto fronteras hacia adentro como hacia afuera de sus naciones. El temor a modos de vida diversos, que puedan afectar los órdenes políticos y sus intereses económicos, son tomados como una justificación suficiente para desencadenar prácticas violentas, aniquilaciones masivas, crecientes faltas de reconocimiento $y$ trato inhumano sobre poblaciones enteras.

Si bien en análisis de Clastres está acotado a un contexto y a un problema particular, creemos que su reflexión no se agota allí, pues bien puede ser puesta en relación con otros procesos y sucesos. Sin 
embargo, en este movimiento de traspolación surgen varios interrogantes, entre los que destacan, por ejemplo, ¿qué elementos serían los que permiten caracterizar un grupo humano como "indeseable"? ¿Qué peligros entraña la diferencia para la unidad? ¿De qué modo se construye el Otro del genocidio y del etnocidio?

Como ya se ha indicado, a lo largo de la historia, cada comunidad a fin de definirse y configurarse, ha puesto en el lugar del Otro a distintos grupos de sujetos, por lo que la otredad no es la misma para todos. Desde esta perspectiva, es posible pensar que el lugar de esa otredad actúa como un significante vacío ${ }^{8}$, que va llenándose según el contexto histórico-político. En síntesis, no habría un Otro generalizado y universal, sino que su construcción depende, cada vez, de las necesidades políticas, sociales e incluso económicas de las configuraciones comunitarias y estatales.

Dado lo anterior, el análisis de Clastres brinda valiosas pistas para pensar el genocidio y el etnocidio en relación a lo político y lo ideológico. En lo que sigue, se reflexionará sobre la otredad que construyeron las juntas militares durante los últimos procesos dictatoriales en el Cono Sur. Si bien dichos procesos fueron diversos, se vislumbran, sin embargo, ciertos elementos comunes, que posibilitaron la implementación de planes de represión y cooperación internacional en la persecución y aniquilación de la otredad.

\section{Hacia la construcción/destrucción del Otro: genocidio y etnocidio}

\section{Breve contextualización de los gobiernos y prácticas dictatoriales en América Latina}

Con el fin de pensar con mayor propiedad la construcción de la otredad durante los gobiernos dictatoriales del Cono Sur, es necesario 
llevar a cabo una contextualización histórico-política del período a analizar. En esta línea, y asumiendo que cada país -Uruguay, Chile y Argentina- vivió esta etapa de modo particular, es posible observar, sin embargo, ciertos sucesos, dispositivos y prácticas que permiten pensar estos procesos políticos en conjunto. Estos elementos comunes, según Marcelo Raffin, se vislumbran en dos registros: uno interno y otro externo. Al aludir a un registro interno, Raffin se refiere a los acontecimientos políticos de cada país en el que se instaló un Estado terrorista que administró la represión, la violencia y la muerte.

"Si se mantienen las viejas categorías de lo político, de lo socioeconómico y de lo cultural para el análisis del universo social, podría decirse que las dictaduras del Cono Sur se apoyaron en, al tiempo que construyeron, un Estado terrorista que fue acompañado asimismo y necesariamente, por la instauración de un cierto modelo social y de una cultura del miedo." (Raffin 2006 157-158).

La metódica y racional administración del terror jugó un papel primordial en la construcción de un Otro disidente. El miedo se materializó en actos represivos, torturas, desapariciones y exilios, que si bien asolaron la cotidianidad de la población, cobraron particular fuerza en los centros clandestinos de represión o campos de concentración ${ }^{9}$. Los centros clandestinos de represión y tortura en Latinoamérica, fueron instituciones creadas por los gobiernos militares de cada país, con el fin de aniquilar física, moral y espiritualmente -como diría Clastres- a los opositores políticos. El quiebre de los Estados de Derecho en el Cono Sur latinoamericano permitió un uso descarnado de la violencia, cuyo fin fue la aniquilación total de aquellos gobiernos más cercanos a la izquierda. Los "procesos de reorganización nacional" instalaron

9 Hemos ya trabajado este tema, al respecto véase: Avila, Mariela. "Dictaduras Latinoamericanas y campos de concentración. Una reflexión filosófica necesaria." En: Dictadura y prisión política en Chile. Compiladores Santos y Pizarro. Santiago de Chile: Editorial Pehuén: 2016. También en: Avila, Mariela. "Estado de excepción y campos de concentración en Chile. Una aproximación biopolítica.". En: Revista Sociedad Hoy, N²5, 2013. Disponible en: [http://www.redalyc.org/pdf/902/90239866005.pdf]. 
un poder desaparecedor (Calveiro 2005 69) que, amparado en las prerrogativas de un Estado de excepción, actuó sobre la población sin ningún tipo de referente ni límite legal. Según Carl Schmitt: "No hay necesidad de que el enemigo político sea moralmente malo, o estéticamente feo (...) El enemigo es simplemente el otro (...)" (2004 177). En este contexto de terrorismo de Estado generalizado, la ausencia de un marco legal posibilitó que una violencia sin nomos se asentara sobre la totalidad de la población (Agamben 2007).

Un interesante documento, elaborado por el Colectivo de Memoria Histórica Corporación José Domingo Cañas, afirma sobre la Doctrina de Seguridad Nacional: "Esta doctrina fue implantada durante la década de 1960 y 70 en toda América Latina, siendo los casos más conocidos en Sudamérica Brasil, 1964-1985; Argentina, 1976-1983; Bolivia, 1971-1978; Uruguay, 1973-1984; y Chile, 1973-1990" (2005 35). La implementación de un conjunto de medidas políticas, económicas y terroristas, respaldadas por pactos clandestinos de cooperación represiva, buscó detener la avanzada de partidos políticos de izquierda en Latinoamérica. La existencia y funcionamiento de dichos pactos dejó en evidencia una gran capacidad de comunicación, coordinación y trabajo conjunto entre las juntas militares: "Cómo se indicó, coordinaron la represión a través de una estrategia conjunta bajo el símbolo del cóndor. En forma análoga al vuelo de esas inmensas aves, el Cono Sur de América quedaba cubierto por un terrorismo organizado y coordinado que no reconocía fronteras" (Raffin 2006 159).

Estos pactos de cooperación internacional tuvieron como fin allanar el terreno para instaurar un modelo de Estado-nación y de ciudadano acorde a los cambios políticos y económicos de corte neoliberal con que se experimentó en la región. Esto se evidencia de modo particular en el caso de Chile. No es casual que en 1975, en Santiago de Chile, se haya llevado a cabo la Primera Reunión de Trabajo de Inteligencia Nacional, en la que se invitó a participar al resto de los países de la región: "Proyectada por el general chileno Contreras, la operación fue suscrita por Argentina, Brasil, Uruguay, Chile y Paraguay" (Raffin 2006 160). Es sabido el importante papel que jugó la CIA en el Plan Cóndor, lo que ha cobrado mayor respaldo y valor documental con 
el descubrimiento del Archivo del Terror en 1992, en Paraguay (Raffin 2006 161). En los pactos de represión conjunta entre los países de la región -bajo la atenta supervisión de los Estados Unidos- se establecieron acuerdos para perseguir, interrogar, expulsar, torturar e incluso asesinar a cualquier sujeto sospechoso de ser subversivo y enemigo del orden. Los pactos de cooperación del Cono Sur se organizaron en torno al arresto de "paquetes" (Calveiro 2008) -término con el que se aludía a los presos políticos-, lo que posibilitaba el intercambio de información y prisioneros. Estas prácticas, fruto de entrenamiento militar internacional, permitieron que las dictaduras contaran con un modus operandi común en la lucha contra la subversión y el marxismo en la región. Dice Calveiro:

“El golpe de 1976 se proponía hacer una operación de "cirugía mayor", que pretendía cambiar el mapa político del país. Tan pretensioso objetivo incluía, entre otras medidas de carácter económico, político y social, la eliminación definitiva del cáncer que amenazaba, desde la perspectiva quirúrgica de los militares, la integridad del cuerpo social." (Calveiro 2008 187).

Si bien la cita anterior se refiere al caso argentino, con los pactos de cooperación internacional instaurados en la región, esta "cirugía mayor" se hace evidente en la totalidad de las dictaduras cívico-militares del Cono Sur. En este contexto emerge y se acentúa la noción de un "sujeto subversivo", de un Otro peligroso contra el que es necesario luchar, pues su postura política, moral y económica podría expandirse como una enfermedad y poner en riesgo la vida de la totalidad de la población. Continúa Calveiro: "Ese cáncer era la llamada "subversión" compuesta no sólo por los militantes de importantes organizaciones armadas sino por todo el espectro político que se oponía al proyecto militar" (Calveiro 2008 187). La metáfora del cáncer, sin duda, alude a la necesidad de erradicación inmediata del órgano enfermo. Si pensamos en los términos de Clastres, la aniquilación de lo diferente es imperiosa, ya que "Se extermina a los otros porque son absolutamente malos" (2001 57). La existencia de ciertos individuos considerados subversivos, que impedían la síntesis social que las juntas militares 
buscaba alcanzar, propició en un marco de ilegitimidad, la violencia, la tortura, el exilio y la muerte.

En el contexto de terrorismo de Estado, era necesario construir e identificar a un Otro como enemigo, que en tanto "subversivo", "upeliento" o "tupamaro", encarnaba una diferencia problemática. Al respecto, y tal como lo hacemos nosotros, Calveiro se pregunta: "¿Cómo se construyó la figura del subversivo?" (2008 188). En lo que sigue, se abordará la pregunta anterior utilizando herramientas conceptuales y categoriales aportadas por Clastres, dado que su reflexión, creemos, brinda nuevas miradas sobre estos acontecimientos y sus consecuencias.

\section{Una aproximación a la lógica binaria de la otredad}

Al instalarse en la lógica del amigo-enemigo (Schmitt 2004), las juntas militares asumieron la existencia de una guerra interna como realidad política y se asignaron la tarea de liberar a la patria de la subversión y el comunismo. La lógica binaria del amigo-enemigo instala el orden bélico en el ámbito de la política y, en el caso del Cono Sur, puso en evidencia el enfrentamiento entre un poder totalizante y grupos menores armados: los defensores de la patria y los Otros, sus "detractores". Al respecto, dice Calveiro:

"Las lógicas totalitarias son lógicas binarias que conciben el mundo como dos grandes campos enfrentados: el propio y el ajeno. Pero además de creer que todo lo que no es idéntico a sí mismo es parte de otro amenazante, el pensamiento autoritario y totalizador entiende que lo diferente constituye un peligro inminente o latente que es preciso conjurar." (Calveiro 2008 88).

Siguiendo la línea de reflexión presentada por Clastres, es posible observar que durante los procesos dictatoriales latinoamericanos, todo aquello que impidiera la unidad del sistema político y económico, era catalogado como diferente y peligroso, convirtiéndose inmediatamente en lo Otro. La lógica binaria propia de estos gobiernos dio cuenta 
que todo elemento distinto al modelo impuesto, debía ser eliminado. En este punto, y siguiendo la línea argumental de este trabajo, cobra preponderancia el factor político e ideológico en relación al genocidio, ya que si bien la diferencia con el Otro puede ser percibida como biológica, es la disidencia política el factor que desencadena prácticas genocidas. Dichas prácticas se materializaron con la implementación de una lógica militar en los espacios públicos y privados, permitiendo actos de barbarie sobre la población como torturas, asesinatos en la vía pública y desapariciones forzadas.

La figura del Otro tiene un papel primordial aquí, pues a partir de un proceso de construcción simbólica y fáctica, se erigió como un enemigo público que se instaló en el tejido social. Las juntas militares caracterizaron esta otredad como amenazante, peligrosa e incluso letal, ya que sus creencias y prácticas políticas la habían llevado a perder sus atributos humanos, al punto de comer "guaguas" o niños, lo que justificaba su aniquilación y desaparición:

"Como el universo se divide entre mis amigos y mis enemigos, todo aquel que potencialmente considere enemigo, pasa a serlo de hecho. Es otro extraño, preferentemente extranjero o infiltrado, un intruso, perfectamente diferente a mí, a quien puedo reconocer de inmediato porque está desprovisto de cualidades humanas." (Calveiro 2008 89).

El elemento primordial en la construcción del enemigo es la diferencia, y en el caso del terrorismo de Estado, fue la disidencia política el factor que se encarnó en el subversivo, el infiltrado, el extranjero. No obstante, es interesante notar que el extranjero no es sólo quien proviene de otro país, sino todo aquel que no concuerda con el modelo de Estado-nación que se buscaba imponer. En este momento de construcción simbólica del Otro, el plano moral juega un papel primordial, pues son los valores o antivalores del subversivo lo que genera una diferencia radical:

"El arquetipo del guerrillero, eje de la subversión, que construyeron los militares lo mostraba como alguien que servía a intereses extranjeros, generalmente comunistas, un 
extraño. (...) En sus vidas privadas no poseía pautas morales de ningún tipo; no valoraba a la familia, abandonaba a sus hijos, sus parejas eran inestables, no se casaba legalmente y se separaba con frecuencia." (Calveiro 2008 94).

En el caso de las mujeres estas descripciones se exacerban, pues la inmoralidad de las guerrilleras tenía una relación directa con su promiscuidad sexual. De hecho, entre las enseñanzas que se impartían en la Escuela de las Américas, sobresalía aquella que caracterizaba a las mujeres militantes como prostitutas (Calveiro 2008 94). La falta de valores morales, así como la falta de humanidad, permitió que los subversivos recibieran un trato in-humano y a la vez des-humanizador. "Voces de amenaza de persecución de muertes inmediatas, de degradación de las personas a un rango no humano, con una tendencia a metamorfosear al "enemigo", retrotrayendo a las personas a su origen primitivo: la animalidad" (Rojas Baeza 2004 167). Es interesante que sea Clastres quien, al analizar las matanzas de indios en América del Sur, indique que "(...) los asesinos de indios llevan al colmo la posición del Otro como diferencia: el indio salvaje no es un ser humano, sino un simple animal" (2001 57). En ambos contextos, y con siglos de diferencia, la falta de humanidad -principio racial básico- propició y justificó la aniquilación del Otro. No tiene mayor sentido cifrar aquí las miles de muertes resultantes de estos procesos de reorganización nacional, sin embargo, la totalidad de estas matanzas se asientan en prácticas aniquiladoras de carácter genocida.

\section{Procesos de reorganización: la desaparición de lo desaparecido}

Tal como indica Feierstein, el genocidio -al que llama "reorganizador" (2014 108), reconfiguró la trama social con la construcción de un Otro caracterizado por sus rasgos negativos. Mediante prácticas genocidas, el cuerpo de ese Otro fue mancillado y asesinado $y$, sin embargo, en el caso latinoamericano, la aniquilación no finalizó con la muerte, sino que implicó además, la desaparición del cadáver: era necesario hacer desaparecer al desaparecido. 
En la primera parte de este trabajo se mostró que el elemento común entre genocidio y etnocidio es la visión del Otro, y que, sin embargo, ambas prácticas tienen un accionar diferente frente a esa otredad. En efecto, mientras que el genocidio busca la eliminación inmediata de la diferencia mediante la aniquilación física, el etnocidio es más "optimista" (Clastres 2001 57), ya que a partir de un sí mismo como modelo, busca la modificación del Otro. Sin embargo, a diferencia del genocidio, la modificación cultural o aniquilación espiritual de carácter genocida sobre un grupo humano no es inmediata, pues puede tomar años antes de evidenciarse.

Quizá una de las novedades de este trabajo, sea la de introducir la categoría de etnocidio al análisis de las últimas dictaduras cívicomilitares del Cono Sur. En efecto, aquí se sostiene que, además de las reconocidas prácticas genocidas, durante estos periodos hubo una clara intencionalidad de reducir toda diferencia de la otredad, dado que "(...) el etnocidio pretende la disolución de lo múltiple en lo Uno." (Clastres 2001 60). En el caso de las juntas militares del Cono Sur, el modelo de reconfiguración y educación del Otro era un reflejo de un "sí mismo", que actuó como elemento unificador. El etnocidio "es la supresión de las diferencias culturales juzgadas inferiores y perniciosas, la puesta en marcha de un proceso de identificación, un proyecto de reducción del otro a lo mismo (...)" (Clastres 2001 61). La necesidad de modificar conductas y formas de vida de la disidencia política era considerada una tarea urgente, cuyos efectos se irían visualizando con el correr del tiempo, ya que la semilla del orden daría sus frutos a partir de una reorganización social y cultural necesaria e inmediata.

Los secuestros, las torturas, las desapariciones forzadas y los exilios, entre otras atrocidades cometidas por la violencia terrorista, operaron como mecanismos que organizaron y resignificaron el cuerpo social. Es decir, con dispositivos y prácticas que pretendían cambiar la conducta de una parte de la población, se instaló el terror y la violencia para anular ciertas formas de vida, a la vez que otras se potenciaban. Así, las juntas militares mediante una correcta reeducación, pretendieron modificar costumbres perniciosas y modos de vida diversos a los del modelo hegemónico que buscaban implementar. La negación de la 
identidad de los secuestrados y asesinados es uno de los modos más evidentes de las prácticas etnocidas. No sólo la muerte implica una negación de identidad, sino también la desaparición de los cuerpos asesinados, y el metódico trabajo en borrar cualquier huella que permitiera el reconocimiento. Este no es el lugar para entrar en detalles sobre métodos de tortura, o formas de evitar el reconocimiento de los cadáveres, sin embargo, es importante evidenciar que la desaparición de los presos políticos, más allá de ser corpórea, fue también espiritual, en términos clastreanos, porque implicó la intención de hacer desparecer modos de existencia en la noche y niebla ${ }^{10}$.

En esta línea, me interesa plantear la que sería, a mi juicio, una de las prácticas etnocidas por excelencia durante los últimos procesos cívicomilitares: el robo de bebés y niños, y la supresión de su identidad. Si el etnocidio persigue la aniquilación cultural, qué mejor modo de lograrlo que aniquilando la posibilidad de herencia y transmisión cultural. El robo de hijos de presos y desparecidos políticos implicó la suplantación de la identidad en más de 400 niños, hijos de militantes, que fueron secuestrados junto a sus padres o que nacieron en los campos de concentración ${ }^{11}$. En muchos casos, estos niños fueron adoptados de modo ilegal por familias de militares, que les dieron una nueva identidad y un modo de vida diverso al que hubiesen tenido con sus

10 En el documental Noche y niebla de 1955, dirigido por Alain Resnais y con guion del poeta francés Jean Cayrol, a partir de documentos, filmaciones y fotografías, se muestra la maquinaria de la muerte puesta en práctica por el nazismo durante el genocidio judío. El título de este documental hace alusión al "Decreto Noche y Niebla" del 7 de diciembre de 1941, con el que el Tercer Reich buscó hacer desaparecer forzadamente la totalidad de sus enemigos -incluidos los prisioneros de guerra- en la noche y en la niebla, esto es, en el olvido y sin dejar rastros de la barbarie. Para mayor información sobre la política del Tercer Reich, Cfr. Kershaw, Ian. La dictadura nazi: problemas y perspectivas de interpretación. Buenos Aires: Siglo XXI Editores, 2004.

11 Según datos del Ministerio de Educación de la Nación Argentina, en un documento que busca sistematizar la información relativa a la última dictadura militar para ser trabajada como propuesta pedagógica en los colegios del país, el número de niños desaparecidos durante el periodo asciende a más de 400. Cfr. Pensar la dictadura: terrorismo de Estado en Argentina. Preguntas, respuestas y propuestas para su enseñanza. En: http://repositorio.educacion.gov.ar/dspace/bitstream/handle/123456789/55770/ Pensar_La_Dictadura\%20\%282\%29.pdf?sequence=1 
padres. La negación y suplantación de la identidad de miembros de la comunidad es un acto etnocida, cuyos efectos son inmediatos, pero también se despliegan en el tiempo, ya que afectan planos subjetivos y sociales. En este sentido, Armando Kletnicki12, afirma:

"Respecto a quien ha sido apropiado ilegalmente, el crimen filiatorio se dirige al menos a dos lugares diferentes: apunta, por un lado, a la supresión de su identidad singular, proponiendo consecuentemente el corte con la generación que lo antecede. Pero es también un crimen que vuelve a desaparecer a sus padres, ya que se orienta en la dirección opuesta a la de la historización de sus biografías personales y de los sucesos de su tiempo." (Feierstein y Levy 2004 168).

El secuestro y la suplantación de la identidad de las nuevas generaciones es una práctica netamente etnocida, ya que busca configurar ciertas existencias de acuerdo a los valores propios, erradicando cualquier huella de diferencia. No es casual que David Blaustein haya denominado Botín de guerra ${ }^{13}$ a su documental sobre la inclaudicable búsqueda de las Abuelas de Plaza de Mayo de sus nietos desparecidos. La mayor aniquilación cultural de un grupo humano reside en erradicar toda posibilidad de perpetuación mediante el robo de sus hijos, como dice Kletnicki "(...) el crimen filiatorio agrega además la complejidad de una tercera muerte, ya que adiciona un corte brutal en la historia singular y colectiva, en tanto interrupción o directamente supresión, en la continuidad de las generaciones." (Feierstein y Levy 2004 168).

\footnotetext{
12 Armando Kletnicki, en su excelente trabajo "Niños desaparecidos: lógica genocida y apropiación ilegal" (Feierstein y Levy 2004), hace una reflexión desde el psicoanálisis acerca de la problemática del crimen filiatorio dese el marco conceptual de los estudios de genocidio. En este artículo hemos decidido desarrollar el análisis del secuestro y apropiación de niños bajo la categoría de "etnocidio" desde el planteo de Pierre Clastres.

13 Documental dirigido por David Blaustein, en el que se narra la lucha de las Abuelas de Plaza de Mayo en la búsqueda de los niños secuestrados y detenidos, durante el Proceso de Reorganización Nacional en Argentina, entre 1976 y 1983.
} 
El problema del secuestro de niños y la supresión de su identidad en contextos dictatoriales, es muy interesante y complejo, por lo que ameritaría en sí mismo una reflexión más profunda y amplia. Sin embargo, esto no se desarrollará aquí, aunque pretendemos hacerlo en ulteriores investigaciones. Por el momento, y a modo de recapitulación, indicamos que la intención de este trabajo ha sido, desde el marco conceptual otorgado por Clastres, evidenciar la existencia de prácticas de carácter genocida y etnocida durante las últimas dictaduras cívico-militares del Cono Sur latinoamericano. Las consecuencias de estas prácticas han tenido sus efectos inmediatos en los periodos políticos mencionados, y sin embargo no han cesado allí, pues sus consecuencias continúan emergiendo y manifestándose aún hoy en nuestra cotidianidad.

\section{A modo de conclusión}

Las conclusiones a las que aquí se arriba presentan un carácter preliminar, es decir, en vez de considerar zanjado el problema, muestran algunos de los posibles puntos de reflexión y apertura epistemológica. Así, entre estos puntos destaca el que sostiene la valía y la novedad que implica el uso de categorías clastreanas para abordar los procesos dictatoriales del Cono Sur. La reflexión de Clastres sobre el genocidio y el etnocidio en particular, permite un nuevo acercamiento al problema del terrorismo de Estado y al modo en que se construye la otredad en base a la diferencia. Siguiendo esta línea, sería posible leer los "procesos de reorganización nacional" de América Latina en clave de genocidio y etnocidio, lo que se evidencia en la construcción y puesta en circulación de la imagen de un sujeto que encarnaba la diferencia frente a la unidad. Precisamente, la existencia de esa otredad que representaba lo ominoso, fue la justificación de las juntas militares para desencadenar prácticas políticas genocidas y etnocidas que, mediante tortura, muerte, desaparición o exilio, intentaron erradicar ciertas existencias y modos de vida del escenario político y social.

De esta forma, y como se ha querido mostrar este trabajo, durante los últimos procesos cívico-militares del Cono Sur, a la par de prácticas 
genocidas, se utilizaron dispositivos de carácter etnocida, con los que se buscó formatear (Calveiro 2008) determinados modos de vida culturales y políticos arraigados en la población. Y en este sentido, hasta el día de hoy se siguen vislumbrando los efectos del etnocidio, pues tal como indica Clastres, sus consecuencias cobran mayor consistencia y visibilidad con el paso del tiempo.

En este trabajo en particular, se ha identificado como una de las principales prácticas etnocidas la apropiación ilegal de niños durante los últimos procesos dictatoriales. En efecto, el secuestro de las generaciones más jóvenes implica un quiebre en el devenir histórico y cultural de una comunidad. Criar a los hijos de esos Otros como propios, busca garantizar la aniquilación de toda herencia, y la asimilación absoluta entre apropiador y apropiado. El intento de reducir lo múltiple y lo diferente a la unidad, cataliza en las historias subjetivas, familiares, comunitarias y nacionales. En este marco, los países del Cono Sur aún hoy buscan instaurar políticas de esclarecimiento, justicia y reparación, que permitan reescribir las diferentes historias, pues las heridas abiertas por prácticas genocidas y etnocidas sobre el cuerpo social perduran aún hoy.

Como se ha indicado ya, las consecuencias del etnocidio se perciben con mayor nitidez con el devenir temporal, pero también lo hacen aquellos procesos subjetivos y sociales que contrastan y resisten sus efectos. De hecho, con el correr de los años, una parte de aquel botín de guerra, más de 120 niños, ha descubierto y recobrado su origen. En el caso de la Argentina, más de 200 niños se han reencontrado con su identidad, con todo lo que ello implica, pudiendo así generar procesos de reorganización y recuperación de sus historias subjetivas, y contribuyendo, sin duda, a la reescritura de las historias colectivas.

\section{Bibliografía}

Agamben, Giorgio. Homo sacer. El poder soberano y la nuda vida. Valencia: Pre-textos, 2006.

Agamben, Giorgio. Estado de excepción. Buenos Aires: Adriana Hidalgo Editora, 2007. 
Arendt, Hannah. Los orígenes del totalitarismo. Madrid: Alianza Editorial, 1987.

Arendt, Hannah. La nature du totalitarisme. Paris: Payot, 1990.

Avila, Mariela. "Narración y comprensión: el lugar de la memoria en la obra de Hannah Arendt". Revista El Banquete de los Dioses. Revista de Filosofía y Teoría Política contemporáneas. Vol. 3, Nº 5, 2015. Disponible en: http:// publicaciones.sociales.uba.ar/index.php/ebdld/article/view/1873/1582

Avila, Mariela. "Dictaduras Latinoamericanas y campos de concentración. Una reflexión filosófica necesaria." En: Dictadura y prisión política en Chile. Compiladores Santos y Pizarro. Santiago de Chile: Editorial Pehuén: 2016.

Avila, Mariela. "Estado de excepción y campos de concentración en Chile. Una aproximación biopolítica.". En: Revista Sociedad Hoy, № 25, 2013. Disponible en: [http://www.redalyc.org/pdf/902/90239866005.pdf].

Calveiro, Pilar. Política y/o violencia. Una aproximación a la guerrilla de los años 70. Buenos Aires: Norma, 2005.

Calveiro, Pilar. Poder y desaparición. Los campos de concentración en Argentina. Buenos Aires: Colihue, 2008.

Clastres, Pierre. Investigaciones en Antropología Política. Barcelona: Gedisa, 2001.

Clastres, Pierre. La sociedad contra el Estado. La Plata: Terramar, 2008.

Colectivo de Memoria Histórica Corporación José Domingo Cañas. Tortura en poblaciones del Gran Santiago (1973-1990). Santiago de Chile; B y J Impresores, 2005.

Feierstein, Daniel y Levy Guillermo. Hasta que la muerte nos separe. Poder y prácticas sociales genocidas en América Latina. La Plata: Ediciones Al Margen, 2004.

Feierstein, Daniel. El genocidio como práctica social. Entre el nazismo y la experiencia argentina. Buenos Aires: Fondo de Cultura Económica, 2007.

Kershaw, lan. La dictadura nazi: problemas y perspectivas de interpretación. Buenos Aires: Siglo XXI Editores, 2004.

Kletnicki, Armando. "Niños desaparecidos: lógica genocida y apropiación ilegal" En Hasta que la muerte nos separe. Poder y prácticas sociales genocidas en América Latina, compiladores Feierstein y Levy. La Plata: Ediciones Al Margen, 2004.

Lacan, Jacques. Escritos 2. México: Siglo XXI, 1971.

Ministerio de Educación de la Nación Argentina. Pensar la dictadura: terrorismo de Estado en Argentina. Preguntas, respuestas y propuestas para su 
enseñanza. En: http://repositorio.educacion.gov.ar/dspace/bitstream/handle/123456789/55770/Pensar_La_Dictadura\%20\%282\%29.pdf?sequence=1

Orestes Aguilar, Héctor. Carl Schmitt, Teólogo de la política. México: Fondo de Cultura Económica, 2004.

Raffin, Marcelo. La experiencia del horror. Subjetividad y derechos humanos en las dictaduras del Cono Sur. Buenos Aires: Del Puerto, 2006.

Rojas Baeza, Paz. "Torturas. Romper el silencio". En De la tortura no se habla. Agüero versus Meneses, compiladora P. Verdugo. Santiago de Chile: Catalonia, 2004. 